\title{
Implementasi Konsep A3 Untuk Mengurangi Reject Proses Assembly
}

\author{
Rahman Soesilo \\ Jurusan Teknik Industri, Pasca Sarjana , Universitas Mercubuana Jakarta \\ Jl. Meruya Sel. No. 1, Kembangan, 11650 Jakarta \\ Surel: rachman_susilo@yahoo.com
}

\begin{abstract}
The A3 concept is one of the Toyota tools to propose problem-solving solutions. A3 provides status reports of ongoing activities. This research applies A3 concept to solve reject problem in plastic company assembling process. The reject rate in the assembly process is $15.6 \%$. The implementation stage of A3 concept is identification of problem, targeting, root cause, goal setting, countermeasure, implementation plan, action and follow up. The A3 concept is in line with the Plan-Do-Check-Act (PDCA) process improvement cycle. The results show that using the concept of $A 3$ can reduce the reject Assembly effectively and precisely.
\end{abstract}

Keywords: Problem solving tools, PDCA, A3 concept, production process

\begin{abstract}
Abstrak
Konsep A3 merupakan salah satu alat yang digunakan Toyota untuk mengusulkan pemecahan masalah. A3 memberikan laporan status kegiatan yang sedang berjalan. Penelitian ini menerapkan konsep A3 untuk menyelesaikan masalah reject di proses assembly perusahaan plastik. Tingkat reject pada proses perakitan sebesar 15,6\%. Tahapan implementasi konsep A3 adalah identifikasi masalah, penentuan target, root cause, penentuan tujuan, usulan perbaikan, rencana pelaksanaan, Action dan tindak lanjut. Konsep A3 sesuai dengan siklus perbaikan proses Plan-Do-Check-Act (PDCA). Hasil penelitian menunjukkan dengan menggunakan konsep A3 dapat mengurangi reject Assembly dengan efektif dan tepat.
\end{abstract}

Kata kunci: Problem solving tools, PDCA, Konsep A3, Proses produksi

\section{Pendahuluan}

Peningkatan kinerja perusahaan dapat dilakukan dengan memperbaiki proses, mengurangi reject, serta mengurangi aktifitas yang tidak perlu atau unnecessary process pada proses produksi [1]. Plan - Do - Check - Action (PDCA) adalah suatu proses pemecahan masalah dengan empat langkah yang digunakan dalam pengendalian kualitas [2]. Metode PDCA dipopulerkan oleh Deming [2]. Deming [2] dianggap sebagai bapak pengendalian kualitas modern. Siklus PDCA disebut dengan siklus Deming. Deming memodifikasi PDCA menjadi PDSA ("Plan, Do, Study, Action"). PDCA sering kali dipergunakan dalam kegiatan Kaizen atau perbaikan berkelanjutan. Konsep PDCA cocok digunakan kegiatan continuous improvement, menghilangkan pemborosan dan meningkatkan produktivitas [3, 4].

Penelitian ini di pabrik plastik "XYZ". Aktivitas utama di pabrik plastik "XYZ" adalah perakitan beberapa part yang menghasilkan produk pump spray. Persaingan produk sejenis yang sangat ketat terutama produk impor dari China menuntut perusahaan agar secara terus menerus untuk melakukan perbaikan proses dan meminimalisasi biaya produksi sehingga dapat berkompetisi di pasar. Pada proses perakitan pump spray terjadi reject yang cukup tinggi yaitu $15.6 \%$.

Salah satu alat untuk perbaikan berkelanjutan adalah Konsep A3. Manfaat dari konsep A3 menurut Visich, et al. [5] antara lain memudahkan pemetaan wewenang dan 
tanggung jawab dari sebuah unit organisasi, sebagai pola kerja dalam perbaikan suatu proses atau sistem di sebuah organisasi, menyelesaikan serta mengendalikan suatu permasalahan dengan pola yang runtun dan sistematis, continuous improvement dalam rangka memperpendek alur kerja, menghilangkan pemborosan di tempat kerja dan meningkatkan produktivitas.

A3 report adalah 1 lembar kertas A3 yang digunakan untuk menunjukan laporan. Seluruh kegiatan perbaikan dapat dilaporkan dengan menggunakan satu lembar kertas A3 [1]. A3 report menggambarkan tentang tidakan perbaikan secara efisien. Kunci untuk menghasilkan A3 report yang baik adalah "Nemawashi" yaitu proses untuk membahas masalah dan potensi solusinya dengan semua pihak yang terkena dampak oleh masalah tersebut [6]. Laporan A3 didasarkan pada siklus PDCA, Tujuan penelitian ini adalah mengimplementasi konsep A3 untuk menurunkan reject Assembly yang terjadi.

\section{Metode Penelitian}

Tahapan implementasi konsep A3 adalah sebagai berikut [5, 7];

Tahap 1. Identifikasi Masalah. Pada tahap identifikasi masalah langkah-langkah yang dilakukan adalah

1. Menggambarkan "situasi yang ideal"

2. Menggambarkan "situasi masalah saat ini"

3. Mengetahui perbedaan antara "situasi yang ideal" dan "situasi saat ini"

4. Membangun tim

Tahap 2. Detail Masalah. Pada tahap ini, langkah-langkah yang dilakukan adalah

1. Mengumpulkan data permasalahan dengan menggunakan bantuan diagram pareto

2. Mengidentifikasi situasi awal dari masalah dengan meninjau proses dengan bantuan Genchi Genbutsu ( "pergi dan melihat")

3. Hanya menangani satu masalah pada saat yang sama (Genchi Genbutsu: "Pergilah langsung ke tempat di mana masalah terjadi dan mengamati proses secara langsung").

Tahap 3. Setting Target. Menetapkan target yang sesuai berdasarkan usulan Sokovic, et al. [8] yaitu SMART (Specific, Measurable, Achievable, Relevant, Time-bound)

Tahap 4. Analisa Akar Masalah. Pada tahap ini, langkah-langkah yang dilakukan adalah

1. Diskusikan untuk mencari penyebab

2. Pilih metode yang sesuai dengan tingkat masalah

3. Mempertanyakan kemungkinan penyebab $\rightarrow$ "Kenapa?"

Tahap 5.Rencana Perbaikan. Pada tahap ini, langkah-langkah yang dilakukan adalah

1. Mengembangkan sebanyak mungkin rencana penanggulangan

2. Mempersempit penanggulangan sesuai dengan probabilitas penyebab

3. Semua anggota tim harus setuju pada solusi / rencana tindakan

4. Mengembangkan rencana tindakan yang jelas dan rinci

Tahap 6. Implementasi. Pada tahap ini, langkah-langkah yang dilakukan adalah

1. Melakukan penanggulangan dengan tim sesuai dengan rencana aksi

2. Share kemajuan dengan komunikasi yang efektif

3. Jangan menyerah atau jangan terburu-buru melanjutkan ke langkah berikutnya

Tahap 7. Hasil Perbaikan. Pada tahap ini, langkah-langkah yang dilakukan adalah

1. Rencana tindakan harus membuktikan adanya hasil dalam menangani masalah.

2. verifikasi perbandingan situasi awal dengan perbaikan harus menggunakan data 
3. Menarik kesimpulan dari tindakan

Tahap 8. Standardisasi. Pada tahap ini, langkah-langkah yang dilakukan adalah

1. Struktur proses sukses (standardisasi)

2. Bagi proses baru dengan Yokoten "menyalin hasil yang baik dari satu daerah ke daerah lain",

3. Mulai putaran berikutnya Kaizen

Gambar 1 menunjukkan template dari A3. Konsep A3 menunjukan laporan dalam 1 lembar kertas ukuran A3 [7]. A3 memudahkan seluruh anggota melihat aktifitas dari suatu proses.

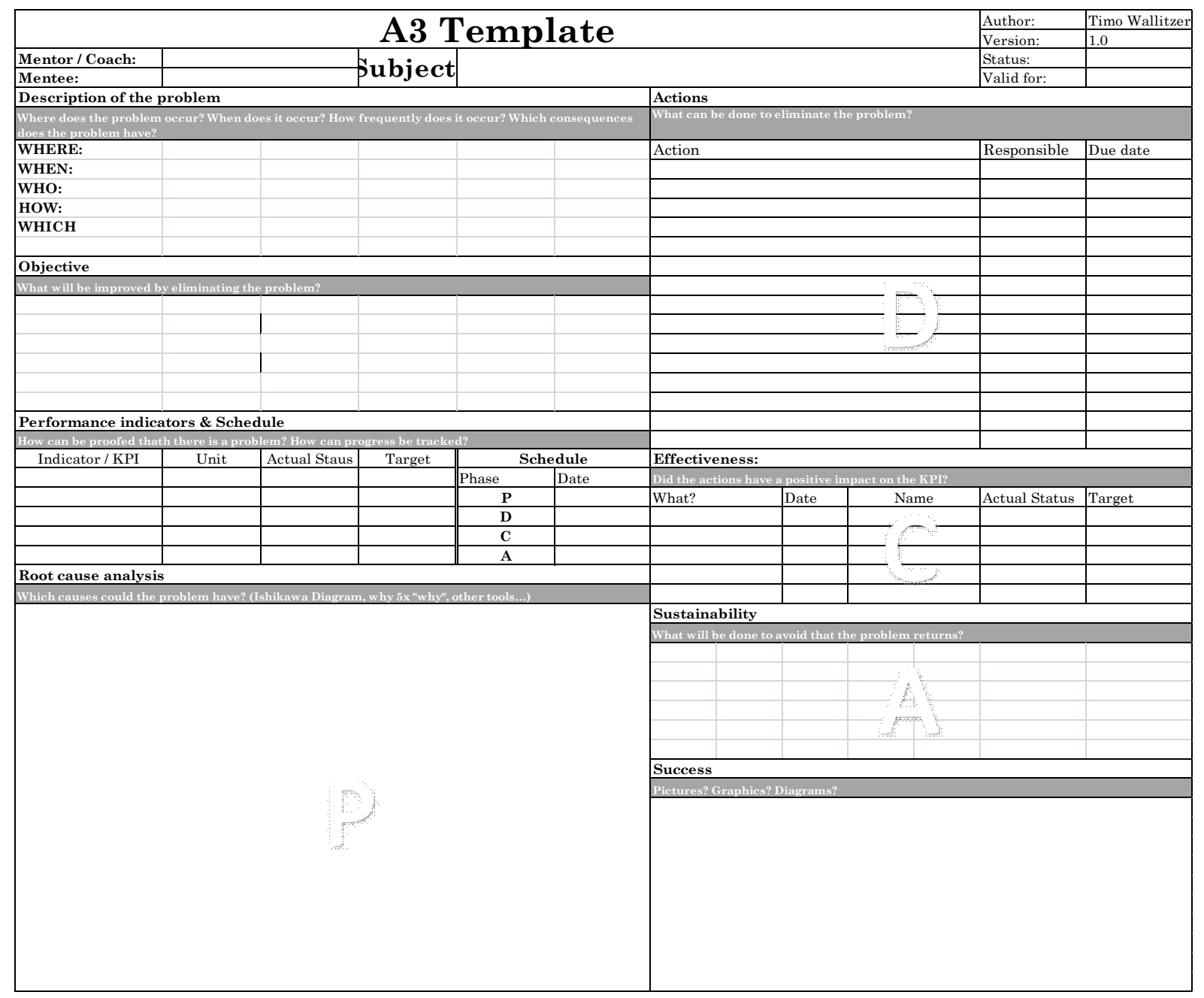

Gambar 1 Template A3 Report

\section{Hasil dan Pembahasan}

Proses perakitan dilakukan otomatis oleh mesin, operator bertugas memasukkan part ke penampungan. Kualitas produk akan sangat tergantung kondisi presisi mesin serta material. Berdasarkan data pengamatan proses perakitan, terjadi reject yang cukup tinggi yaitu $15.6 \%$. Data pengamatan selama 1 minggu dapat dilihat pada Tabel 1. Tahap pertama dalam penerapan konsep A3 adalah membentuk tim pengurangan reject dan menentukan kondisi ideal. 
Tabel 1. Data produk reject

\begin{tabular}{|c|c|c|c|c|c|c|}
\hline DATE & Shift & PO.NO & $\begin{array}{l}\mathrm{OPR} \\
\mathrm{M} / \mathrm{C} \\
\end{array}$ & $\begin{array}{c}\text { TOTAL } \\
\text { PROD. }\end{array}$ & TOTAL & $\begin{array}{c}\text { REJECT } \\
\% \\
\end{array}$ \\
\hline 01-Dec-16 & 3 & 711007165 & Sendi & 36.000 & 1.872 & 5,20 \\
\hline \multirow[t]{2}{*}{ 02-Dec-16 } & 1 & 711007165 & Rifai & 30.000 & 1.979 & 6,60 \\
\hline & 3 & 711007165 & Sendi & 25.000 & 1.896 & 7,58 \\
\hline \multirow[t]{5}{*}{ 03-Dec-16 } & 1 & 711007252 & Rifai & 22.000 & 3.633 & 16,51 \\
\hline & 1 & 711007239 & Rifai & 5.000 & 1.843 & 36,86 \\
\hline & 2 & 711007239 & Dede R & 25.000 & 6.746 & 26,98 \\
\hline & 3 & 711007165 & Sendi & 23.000 & 1.584 & 6,89 \\
\hline & 3 & 711007241 & Sendi & 14.000 & 968 & 6,91 \\
\hline \multirow[t]{2}{*}{ 04-Dec-16 } & 1 & 711007241 & Rifai & 11.000 & 838 & 7,62 \\
\hline & 3 & 711007253 & Sendi & 30.000 & 9.319 & 31,06 \\
\hline \multirow[t]{3}{*}{ 05-Dec-16 } & 1 & 711007253 & Rifai & 36.000 & 12.857 & 35,71 \\
\hline & 3 & 711007165 & Ade Evan & 20.000 & 1.992 & 9,96 \\
\hline & 3 & 711007253 & Ade Evan & 12.000 & 4.921 & 41,01 \\
\hline \multirow[t]{2}{*}{ 06-Dec-16 } & 1 & 711007253 & Nasam & 22.000 & 5.808 & 26,40 \\
\hline & 3 & 711007165 & Heri & 20.000 & 2.905 & 14,53 \\
\hline \multirow[t]{2}{*}{ 08-Dec-16 } & 2 & 711007165 & Subari & 40.000 & 3.277 & 8,19 \\
\hline & 3 & 711007165 & Daryanto & 7.000 & 606 & 8,66 \\
\hline \multirow[t]{2}{*}{ 09-Dec-16 } & 1 & 711007253 & Kusnadi & 20.000 & 6.128 & 30,64 \\
\hline & 3 & 711007249 & Daryanto & 38.000 & 3.795 & 9,99 \\
\hline \multirow[t]{4}{*}{ 10-Dec-16 } & 1 & 711007249 & Alwi & 7.000 & 769 & 10,99 \\
\hline & 1 & 711007165 & Alwi & 22.000 & 1.409 & 6,40 \\
\hline & 2 & 711007165 & Subari & 28.000 & 2.980 & 10,64 \\
\hline & 3 & 711007165 & Hendra $\mathrm{s}$ & 20.000 & 2.465 & 12,33 \\
\hline \multirow[t]{7}{*}{ 11-Dec-16 } & 1 & 711007165 & Alwi & 12.000 & 1.037 & 8,64 \\
\hline & 1 & 711007264 & Alwi & 15.000 & 2.257 & 15,05 \\
\hline & 2 & 711007165 & subari & 18.000 & 2.338 & 12,99 \\
\hline & 2 & 711007165 & subari & 7.000 & 800 & 11,43 \\
\hline & 2 & 711007266 & subari & 10.000 & 1.650 & 16,50 \\
\hline & 3 & 711007270 & Hendra & 15.000 & 2.006 & 13,37 \\
\hline & 3 & 711007277 & Hendra & 10.000 & 1.395 & 13,95 \\
\hline \multirow[t]{2}{*}{ 12-Dec-16 } & 3 & 711007268 & subari & 10.000 & 255 & 2,55 \\
\hline & 3 & 711007270 & Hendra & 9.000 & 1.024 & 11,38 \\
\hline \multirow[t]{5}{*}{ 13-Dec-16 } & 1 & 711007270 & Kusnadi & 6.000 & 474 & 7,90 \\
\hline & 1 & 711007289 & Kusnadi & 7.000 & 968 & 13,83 \\
\hline & 2 & 711007289 & subari & 5.000 & 946 & 18,92 \\
\hline & 3 & 711007289 & Vrenky & 9.500 & 1.557 & 16,39 \\
\hline & 3 & 711007286 & Vrenky & 17.000 & 2.349 & 13,82 \\
\hline \multirow[t]{2}{*}{ 15-Dec-16 } & 2 & 711007286 & Candra & 38.000 & 7.239 & 19,05 \\
\hline & 3 & 711007286 & Agus S & 19.000 & 3.092 & 16,27 \\
\hline \multirow[t]{4}{*}{ 18-Dec-16 } & 1 & 711007293 & Subari & 12.000 & 4.681 & 39,01 \\
\hline & 2 & 711007295 & M. Furkon & 12.000 & 1.983 & 16,53 \\
\hline & 2 & 711007297 & M. Furkon & 12.000 & 1.831 & 15,26 \\
\hline & 3 & 711007286 & Agus S & 38.000 & 6.287 & 16,54 \\
\hline 19-Dec-16 & 1 & 711007286 & Subari & 21.200 & 3.157 & 14,89 \\
\hline \multirow[t]{2}{*}{ 20-Dec-16 } & 1 & 711007316 & Subari & 14.000 & 2.061 & 14,72 \\
\hline & 2 & 711007316 & Anwarudin & 11.000 & 1.580 & 14,36 \\
\hline
\end{tabular}

Setelah mengamati produk reject, tim menentukan jenis kecacatan terbesar dengan menggunakan diagram pareto. Diagram pareto digunakan untuk mengetahui jenis kecacatan terbesar. Diagram pareto dapat dilihat pada Gambar 2.

Dari Gambar 2 diketahui bahwa jenis reject bad patern merupakan jenis reject terbesar. Tim melakukan diskusi untuk menentukan atau menganalisis masalah yang menyebabkan reject. Hasil diskusi tim digambarkan dalam bentuk Fish Bone Diagram atau Diagram Ishikawa. Hasil analisa Fish bone diagram menunjukkan perbaikan di material dan mesin sebagai tahap awal dari tindakan perbaikan. Gambar Fish bone diagram dapat dilihat pada Gambar 3. 


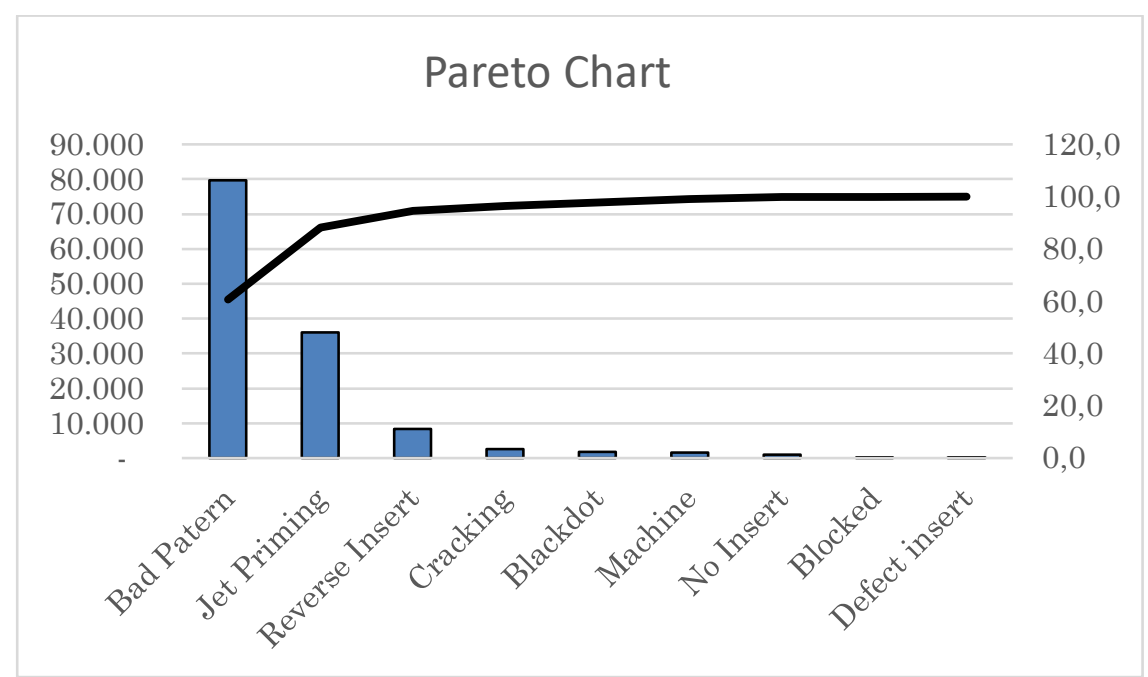

Gambar 2 Diagram pareto jenis reject

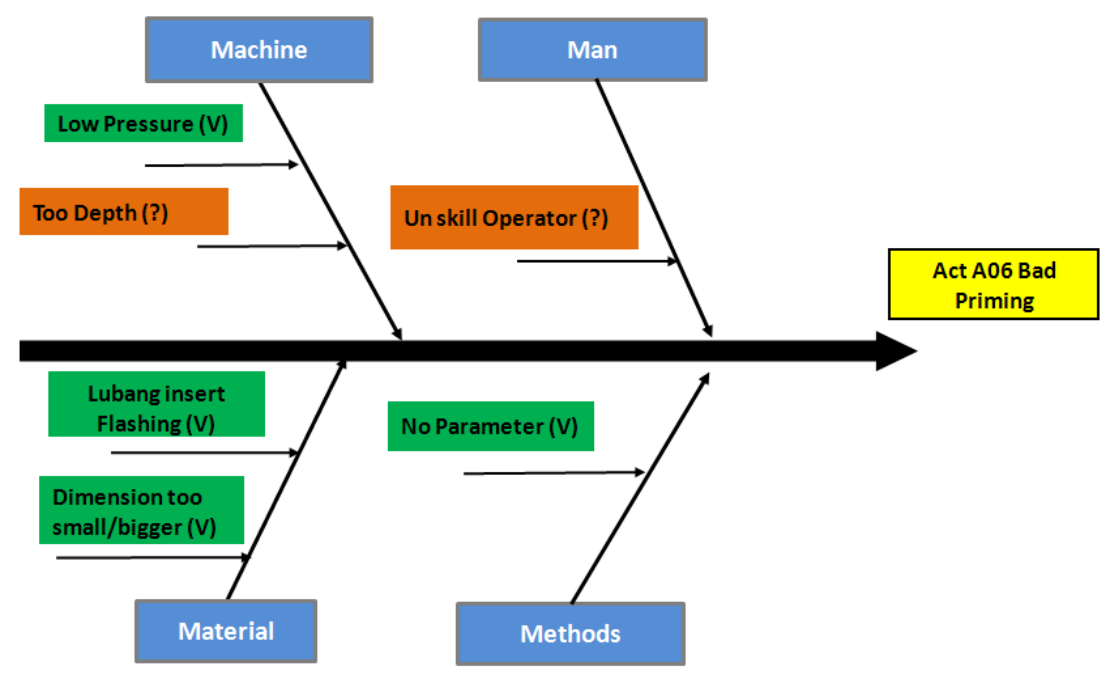

Gambar 3 Fish bone diagram

Tahapan berikutnya adalah melakukan pengukuran lebih detail mengenai diameter komponen. Beberapa komponen tidak sesuai dengan standar. Hasil dari pengukuran masing - masing diameter, terdapat komponen diluar standar perusahaan. Tim harus segera melakukan perbaikan masalah reject. Tim memberikan usulan perbaikan yaitu mengganti alat sesuai standar. Hasil perbaikan yang dilakukan oleh tim dapat menurunkan reject proses assembly menjadi 6,6\%. Tim harus melakukan perbaikan secara terus-menerus hingga mencapai reject seminimal mungkin. Tahap akhir adalah memasukkan ke template A3. Hasil lengkap dari A3 report tersebut dilihat pada Gambar 4.

\section{Simpulan}

Penerapan A3 konsep dalam perbaikan proses menghasilkan penurunan reject menjadi 6,6\%. Konsep A3 dapat mengarahkan arah perbaikan menjadi tepat sehingga sesuai dengan target. A3 Report mudah dipahami karena dalam keseluruhan proses digambarkan dalam 1 lembar kertas saja. 


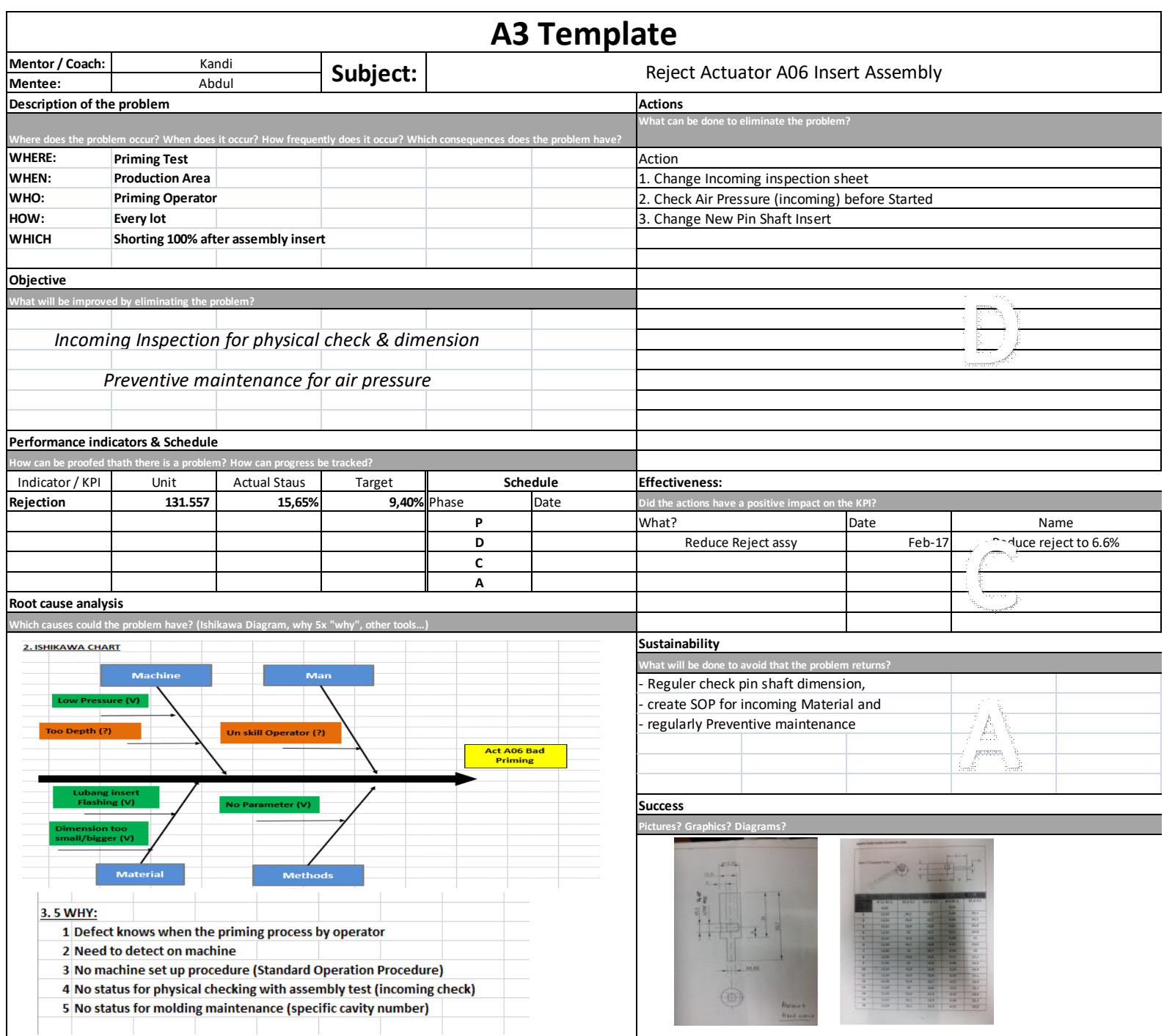

\section{Gambar 4 Report A3}

\section{Referensi}

[1] J. K. Liker, Becoming lean: Inside stories of US manufacturers: CRC Press, 1997.

[2] W. E. Deming, "Out of the crisis. Massachusetts Institute of Technology," Center for advanced engineering study, Cambridge, MA, vol. 510, 1986.

[3] P. D. Paramita, "Penerapan Kaizen Dalam Perusahaan," Dinamika Sains, vol. 10, 2012.

[4] R. Puspita, "Konsep Kaizen Untuk Meningkatan Kualitas Secara Terus Menerus Pada Industri Sarung Tangan Kesehatan," MIEJ, vol. 3, 2014.

[5] J. K. Visich, A. M. Wicks, and F. Zalila, "Practitioner perceptions of the A3 method for process improvement in health care," Decision Sciences Journal of Innovative Education, vol. 8, pp. 191-213, 2010.

[6] J. Liker, The Toyota way fieldbook: Esensi, 2006.

[7] D. K. Sobek II and C. Jimmerson, "A3 reports: tool for process improvement," in IIE Annual Conference. Proceedings, 2004, p. 1.

[8] M. Sokovic, D. Pavletic, and K. K. Pipan, "Quality improvement methodologiesPDCA cycle, RADAR matrix, DMAIC and DFSS," Journal of Achievements in Materials and Manufacturing Engineering, vol. 43, pp. 476-483, 2010. 